\title{
Omalizumab effectiveness in patients with severe allergic asthma according to blood eosinophil count: the STELLAIR study
}

\author{
Marc Humbert ${ }^{1,2,3}$, Camille Taillé ${ }^{4}$, Laurence Mala ${ }^{5}$, Vincent Le Gros ${ }^{5}$, \\ Jocelyne Just $^{6}$ and Mathieu Molimard ${ }^{7}$ on behalf of the STELLAIR investigators ${ }^{8}$ \\ Affiliations: ${ }^{1}$ Université Paris-Sud, Faculté de Médecine, Université Paris-Saclay, Le Kremlin-Bicêtre, France. \\ ${ }^{2}$ AP-HP, Service de Pneumologie, Hôpital Bicêtre, Le Kremlin-Bicêtre, France. ${ }^{3}$ INSERM UMR_S 999, Hôpital \\ Marie Lannelongue, Le Plessis Robinson, France. ${ }^{4} \mathrm{AP}-\mathrm{HP}$, Hôpital Bichat, Service de Pneumologie et Centre \\ de Référence des Maladies Pulmonaires Rares, Dépt Hospitalo-Universitaire FIRE, Université Paris Diderot, \\ INSERM UMR 1152, Paris, France. ${ }^{5}$ Novartis Pharma SAS, Rueil-Malmaison, France. ${ }^{6}$ Université Paris \\ Sorbonne, AP-HP, Service d'Allergologie Pédiatrique (Centre de l'Asthme), Hôpital Trousseau, Paris, France. \\ ${ }^{7}$ Dept of Medical Pharmacology, Université de Bordeaux, INSERM UMR 1219, Bordeaux, France. ${ }^{8} \mathrm{~A}$ list of the \\ STELLAIR investigators can be found in the Acknowledgements section.
}

Correspondence: Marc Humbert, Service de Pneumologie, Hôpital Bicêtre, 78 Rue du général Leclerc, 94270 Le Kremlin-Bicêtre, France. E-mail: marc.humbert@aphp.fr

@ERSpublications

Omalizumab is a treatment option for severe allergic asthma irrespective of blood eosinophil count http://ow.ly/7tQh30iXNTW

Cite this article as: Humbert M, Taillé C, Mala L, et al. Omalizumab effectiveness in patients with severe allergic asthma according to blood eosinophil count: the STELLAIR study. Eur Respir J 2018; 51: 1702523 [https://doi.org/10.1183/13993003.02523-2017].

ABSTRACT Omalizumab is a monoclonal anti-IgE antibody used to treat severe allergic asthma (SAA). The aim of the STELLAIR study was to determine the importance of pre-treatment blood eosinophil count as a predictive measure for response to omalizumab.

This retrospective real-life study was conducted in France between December 2015 and September 2016 using medical records of SAA omalizumab-treated patients. Response to omalizumab was assessed by three criteria: physician evaluation, reduction of $\geqslant 40 \%$ in annual exacerbation rate and a combination of both. Response rate was calculated according to blood eosinophil count measured in the year prior to omalizumab initiation.

872 SAA omalizumab-treated patients were included by 78 physicians ( 723 adults (age $\geqslant 18$ years) and 149 minors (age $6-17$ years)). Blood eosinophil count was $\geqslant 300$ cells $\mu \mathrm{L}^{-1}$ in $52.1 \%$ of adults and $73.8 \%$ of minors. By physician evaluation, $67.2 \%$ of adults and $77.2 \%$ of minors were responders and $71.1 \%$ adults and $78.5 \%$ minors had $\mathrm{a} \geqslant 40 \%$ reduction in the exacerbation rate. In adults, the response rate for combined criteria was $58.4 \%$ (95\% CI 53.2-63.4\%) for blood eosinophils $\geqslant 300$ cells $\mu \mathrm{L}^{-1}(\mathrm{n}=377)$ and $58.1 \%$ (95\% CI 52.7-63.4\%) for blood eosinophils $<300$ cells $\mu \mathrm{L}^{-1}(\mathrm{n}=346)$.

This study shows that a large proportion of patients with SAA have a blood eosinophil count $\geqslant 300$ cells. $\mu \mathrm{L}^{-1}$, and suggests that omalizumab effectiveness is similar in "high" and "low" eosinophil subgroups. 


\section{Introduction}

Severe asthma is a heterogeneous disease with several phenotypes including allergic and eosinophilic asthma [1,2]. About 70\% of asthmatic patients are allergic [3]. Allergens that enter the airway are presented to T-lymphocytes by dendritic cells that initiate the cell-mediated immune response, particularly the maturation and migration of type 2 T-helper cells (Th2). Th2 cells stimulate B-cells to produce IgE antibodies as well as stimulate secretion of pro-allergic cytokines, such as interleukins (IL)-4, $-5,-9$ and -13. IL-4 is essential for the production of IgE, whereas IL-5 is involved in the recruitment of eosinophils and basophils, which then promote inflammation.

A humanised anti-IgE monoclonal antibody, omalizumab, indicated as an add-on therapy for children (from the age of 6 years) and adults with uncontrolled persistent severe allergic asthma (SAA), was first introduced in Europe in $2005[4,5]$. Omalizumab has been shown to prevent exacerbations, to improve symptoms and quality of life, and to decrease systemic corticosteroid use both in large-scale randomised studies [6-8] and "real-life" studies [9-15].

Novel therapies that target IL-5 or its receptor in the same Th2 pathway are emerging for the treatment of severe eosinophilic asthma (SEA) [16]. The clinical benefits of these therapies are more pronounced in patients with a high blood eosinophil count and their indication is consequently restricted to adults with refractory SEA defined by a blood eosinophil count $\geqslant 300$ cells $\mu \mathrm{L}^{-1}$ over 12 months [16]. Interestingly, a large proportion of patients with SAA also have a blood eosinophil count $\geqslant 300$ cells $\mu \mathrm{L}^{-1}$ [17].

The aim of the STELLAIR (Next Steps Toward personalised care: EvaLuating responders to XoLAIR treatment in patients with SAA) study was to determine the importance of pre-treatment blood eosinophil count as a predictive measure for response to omalizumab.

\section{Methods}

\section{Study design and participants}

This multicentre, noninterventional, retrospective, observational study was performed in France from December 21, 2015 to September 30, 2016, using data from medical records of patients with SAA treated with omalizumab. Hospital-based pulmonologists and paediatric pulmonologists with experience in treating severe asthma were asked to provide data of all their consecutive patients meeting the STELLAIR inclusion criteria. Physicians could include consecutive patients meeting inclusion criteria up to a maximum of 30 patients per physician. STELLAIR is a retrospective noninterventional study, which does not require registration on ClinicalTrials.gov. This real-life study was approved by the institutional committees in charge of data protection in biomedical research in France (Comité Consultatif sur le Traitement de l'Information en matière de Recherche and Commission Nationale de l'Informatique et des Libertés).

Inclusion criteria were any patient: $\geqslant 6$ years of age; who had been treated with omalizumab for poorly controlled SAA; with a documented blood eosinophil measurement taken within 12 months prior to omalizumab treatment initiation; with the number of exacerbations recorded during the 12 months prior to omalizumab initiation; and who had a documented physician evaluation of response to omalizumab after 4-6 months of treatment and number of exacerbations recorded. Patients that refused collection of their medical data for research purposes were excluded in accordance with the ethics committee requirements.

Investigators entered patient data in an electronic case report form and extracted data for four time-points: $\mathrm{T}-12$ corresponding to the 12 months prior to omalizumab initiation, To corresponding to time of omalizumab treatment initiation, T4-6 corresponding to first effectiveness assessment at 4-6 months of treatment (as required in the omalizumab summary of product characteristics) and T12 corresponding to effectiveness assessment at 12 months following treatment initiation (12-month effectiveness evaluation for renewal of prescription, if available). The study being retrospective, T4-6 and T12 (if available) were prior to the study start in December 2015.

\section{Outcomes}

The primary outcome was response to omalizumab treatment at T4-6 compared with T-12 using three criteria.

1) The physician's overall evaluation according to the Global Evaluation of Treatment Effectiveness (GETE) scale. GETE is a five-point scale, where 1=excellent (complete control of asthma), 2=good (marked improvement), 3=moderate (discernible, but limited improvement), 4=poor (no appreciable change) and 5=worsening. The rating of symptoms control as "excellent"/"good" or "moderate"/"poor"/ "worsening" allowed the patient to be defined as a "responder" or "nonresponder", respectively. 
2) A decrease in the annual exacerbation rate, with a "responder" defined as having a reduction in the annual exacerbation rate of $\geqslant 40 \%$. An asthma exacerbation was defined as a significant worsening of asthma requiring a short burst of oral corticosteroids (OCSs) or, for patients treated with an OCS, an increase in the OCS dose regimen. The annual exacerbation rate was calculated by adjusting the number of exacerbations according to the duration of exposure to omalizumab treatment; treatment duration was 46 months for all patients and 12 months for 706 patients (81\%).

3) A combination of the GETE evaluation and $a \geqslant 40 \%$ reduction in the annual exacerbation rate ("combined response").

Response was analysed according to blood eosinophil count (cells. $\mu \mathrm{L}^{-1}$ ) measured in the year prior to omalizumab initiation (last measurement available prior to initiation).

\section{Statistical analysis}

Statistical analysis was performed using SAS version 9.4 (SAS Institute, Cary, NC, USA). Descriptive analyses of qualitative variables are expressed as number of patients for each category and percentage. Quantitative variables are presented as mean and standard deviation for normally distributed variables or as median and interquartile range (IQR) when not. The 95\% confidence intervals are indicated for each of the three outcome end-points. The number of missing values is reported for each variable, where indicated. All statistical tests were two-sided and the $\alpha$ risk was set at $5 \%$.

\section{Results}

Of the 510 physicians who were invited to participate, 102 accepted and 80 sites were finally opened; of these, 78 (62 pulmonologists and 16 paediatric pulmonologists) actively recruited a total of 879 patients who met the eligibility criteria. 872 of these patients, of whom $723(83 \%)$ were adults (age $\geqslant 18$ years) and 149 (17\%) were minors (age 6-17 years), were included in the study (figure 1). Seven patients, all $\geqslant 18$ years of age, were excluded from analysis due to incomplete medical records at $T 4-6(n=5)$ or because there was no documentation of other asthma controller treatments $(n=2)$.

Most of the patients $(\mathrm{n}=804(92.2 \%))$ were still being treated with omalizumab after the first effectiveness assessment at T4-6 and $81 \%(\mathrm{n}=706)$ had a follow-up at T12, i.e. 12 months after omalizumab initiation.

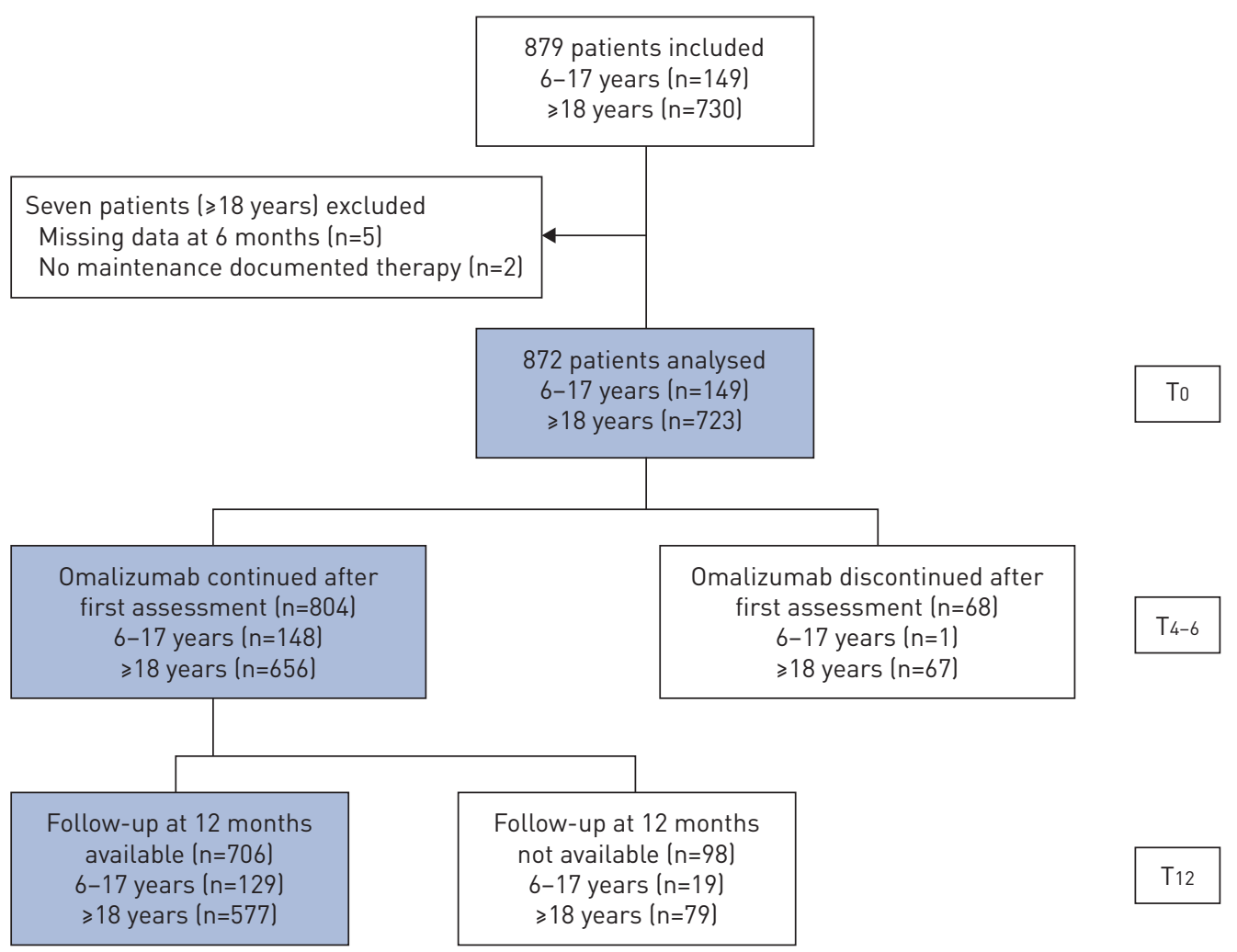

FIGURE 1 Study flowchart. T0: omalizumab treatment initiation; T4-6: first effectiveness assessment after 4-6 months of treatment; T12: effectiveness assessment at 12 months following treatment initiation. 
Patient characteristics are presented in table 1. For adults and minors, omalizumab was prescribed as an add-on therapy to improve asthma control in patients who had multiple documented severe asthma exacerbations despite daily high-dose inhaled corticosteroid (ICS), plus a long-acting $\beta_{2}$-agonist (LABA) with or without OCS treatment. At T0, more than a third of the adult patients $(n=243(34.4 \%))$ were

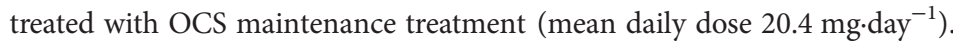

All the patients included in this study had uncontrolled SAA, as reflected by the number of asthma events in the previous 12 months (exacerbations: mean $\pm \mathrm{SD} 5.2 \pm 3.9$ in minors and $4.3 \pm 3.1$ in adults; frequent unplanned hospitalisations: 79 (53\%) in minors and 295 (40.8\%) in adults). Exacerbations and hospitalisations in the 12 months prior to omalizumab by blood eosinophil count in minors and adults are shown in table 2.

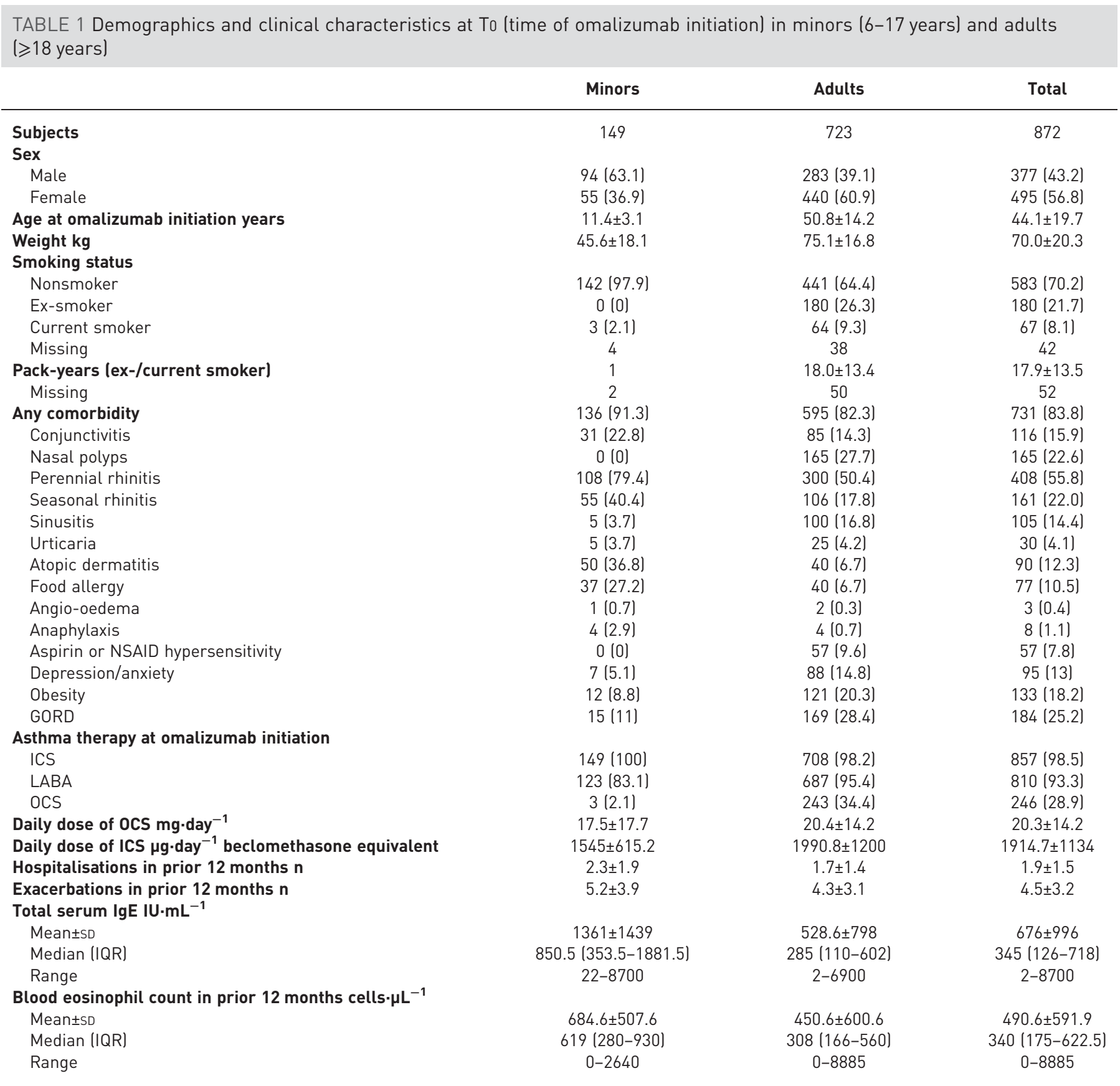

Data presented as $\mathrm{n}$, mean \pm SD or $\mathrm{n}(\%)$, unless otherwise stated. NSAID: nonsteroidal anti-inflammatory drug; GORD: gastro-oesophageal reflux disease; ICS: inhaled corticosteroid; LABA: long-acting $\beta_{2}$-agonist; OCS: oral corticosteroid; IQR: interquartile range. 
TABLE 2 Exacerbations and hospitalisations before omalizumab initiation by blood eosinophil count measured in the year prior to omalizumab initiation ( $T-12)$ in minors $(6-17$ years) and adults $(\geqslant 18$ years)

\begin{tabular}{|c|c|c|c|c|c|c|}
\hline & \multicolumn{2}{|c|}{$<300$ cells $\cdot \mu \mathrm{L}^{-1}$} & \multicolumn{2}{|c|}{$\geqslant 300$ cells $\cdot \mu \mathrm{L}^{-1}$} & \multicolumn{2}{|c|}{ Total } \\
\hline & Minors & Adults & Minors & Adults & Minors & Adults \\
\hline Subjects & 39 & 346 & 110 & 377 & 149 & 723 \\
\hline Hospitalisations n & $2.1 \pm 1.7(1.5-2.8)$ & $1.8 \pm 1.6(1.6-2.1)$ & $2.4 \pm 2.1(1.8-2.9)$ & $1.7 \pm 1.1(1.5-1.8)$ & $2.3 \pm 1.9(1.9-2.7)$ & $1.7 \pm 1.4(1.6-1.9)$ \\
\hline
\end{tabular}

Data are presented as $\mathrm{n}$ or mean \pm SD $(95 \% \mathrm{Cl})$.

In minors, this severe allergic population was characterised by very high total IgE levels (median IgE level $\left.850 \mathrm{IU} \cdot \mathrm{mL}^{-1}\right)$. In adults, the median total serum IgE level was $285 \mathrm{IU} \cdot \mathrm{mL}^{-1}$.

The median blood eosinophil count at $\mathrm{T}-12$ was more than twice as high in minors compared with adults (619 versus 308 cells $\mu \mathrm{L}^{-1}$ ) (table 3 ). The distribution of the blood eosinophil count at $\mathrm{T}-12$ ranged from 0 to $\geqslant 1000$ cells $\mu \mathrm{L}^{-1}$ and was on average higher in minors than adults. 377 adult SAA patients (52.1\%) had blood eosinophils $\geqslant 300$ cells $\mu \mathrm{L}^{-1}$.

Omalizumab effectiveness was first evaluated at T4-6 by the treating pulmonologist or paediatrician using the GETE scale after a median of 154 days of treatment: $77.2 \%$ minors $(n=115)$ and $67.2 \%$ adults $(n=486)$ were reported to be responders (i.e. excellent (complete control) or good (marked improvement of asthma)) to omalizumab (figure 2).

During the treatment period, between T0 and T4-6, 34.9\% of minors $(n=52)$ and $43 \%$ of adults $(n=311)$ presented at least one exacerbation. The mean number of exacerbations in patients with at least one exacerbation was 1.9 in minors and 1.8 in adults. The mean \pm SD decrease in the annual exacerbation rate was $60.2 \pm 88.8 \%$ in minors and $48.5 \pm 93.5 \%$ in adults. Most of the patients were classified as responders according to the reduction in the annual exacerbation rate (reduction of $\geqslant 40 \%$ ): $78.5 \%$ (95\% CI 71.1 $84.8 \%)$ of minors and $71.1 \%(95 \%$ CI $67.6-74.4 \%)$ of adults.

A combined response to omalizumab treatment (combination of GETE and exacerbation rate decrease) was reached in $67.8 \%$ (95\% CI 59.7-75.2\%) and 58.2\% (95\% CI 54.5-61.8\%) of minors and adults, respectively.

Among the 723 adults, 377 had blood eosinophils $\geqslant 300$ cells $\mu \mathrm{L}^{-1}$ and 346 had blood eosinophils $<300$ cells $\mu \mathrm{L}^{-1}$. In adults, the GETE response, $\geqslant 40 \%$ reduction of exacerbation response and combined response rates to omalizumab treatment were similar irrespective of the blood eosinophil count, using a cut-off of either 300 or 150 cells $\mu \mathrm{L}^{-1}$ (figure 3). Moreover, the proportion of combined response was

TABLE 3 Blood eosinophil counts measured in the 12 months prior to omalizumab initiation $(T-12)$ in minors $(6-17$ years) and adults $(\geqslant 18$ years)

\begin{tabular}{lccc} 
& Minors & Adults & Total \\
\hline $\begin{array}{l}\text { Subjects } \\
\text { Delay from CBC to omalizumab initiation months }\end{array}$ & 149 & 723 & 872 \\
OCS maintenance treatment at CBC & $2.8 \pm 2.8$ & $3.1 \pm 3$ & $3 \pm 2.9$ \\
$\quad$ Yes & $5(3.4)$ & $216(30.9)$ & $221(26.2)$ \\
$\quad$ No & $141(96.6)$ & $483(69.1)$ & $624(73.8)$ \\
$\quad$ Missing & 3 & 24 & 27 \\
Eosinophil count cells: $\boldsymbol{\mu L}^{-1}$ & & & \\
$\quad<150$ & $17(11.4)$ & $163(22.5)$ & $180(20.6)$ \\
$\geqslant 150$ & $132(88.5)$ & $560(77.5)$ & $692(79.4)$ \\
$\geqslant 300$ & $110(73.8)$ & $377(52.1)$ & $487(55.8)$ \\
$\geqslant 400$ & $98(65.8)$ & $291(40.2)$ & $389(44.6)$ \\
$\geqslant 500$ & $87(58.4)$ & $221(30.6)$ & $308(35.3)$ \\
$\geqslant 1000$ & $32(21.5)$ & $56(7.7)$ & $88(10.1)$ \\
\hline
\end{tabular}

Data are presented as $\mathrm{n}$, mean \pm SD or $\mathrm{n}(\%)$. CBC: cell blood count; OCS: oral corticosteroid. 


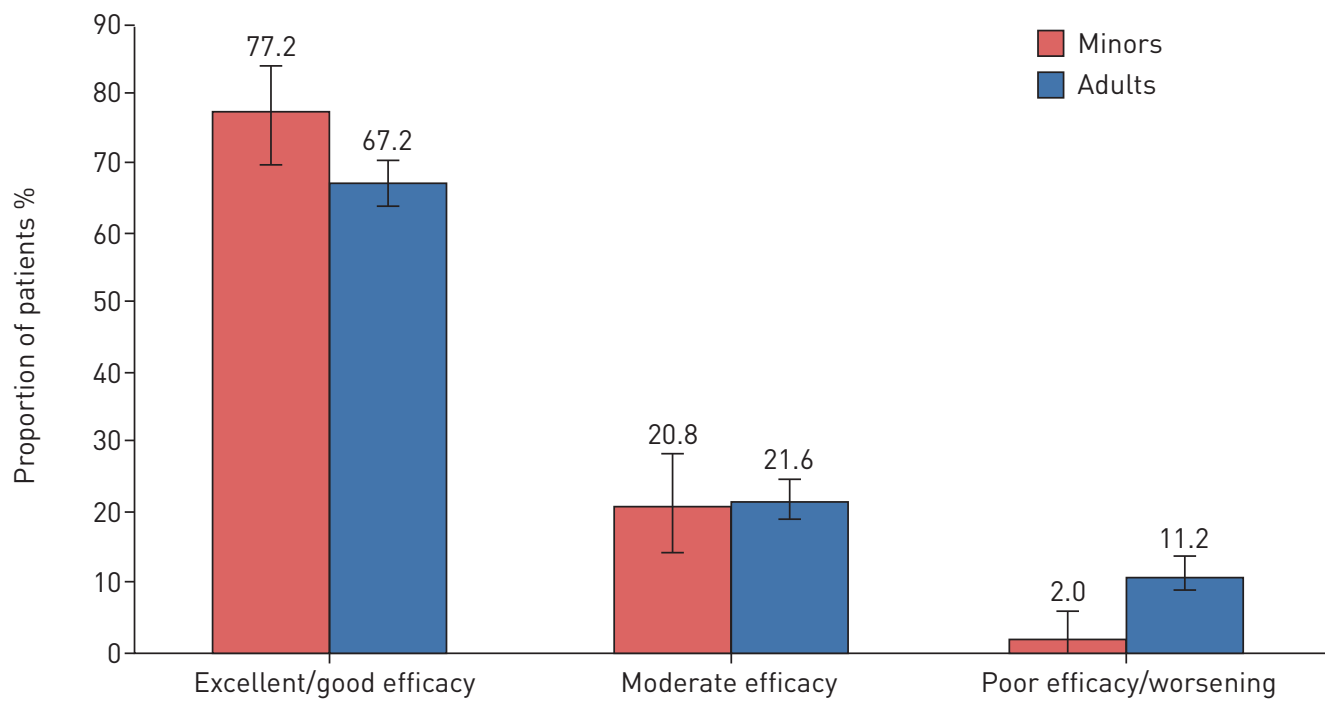

FIGURE 2 Global Evaluation of Treatment Effectiveness evaluation at T4-6 (time of first effectiveness assessment after $4-6$ months of treatment) by age group: minors (age $6-17$ years; $n=149$ ) and adults lage $\geqslant 18$ years; $n=723$ ). Error bars indicate $95 \%$ confidence intervals.

similar for "low" eosinophils $\left(<300\right.$ cells $\left.\mu \mathrm{L}^{-1}\right)$ and "high" eosinophils $\left(\geqslant 300\right.$ cells $\left.\mu \mathrm{L}^{-1}\right)$ in the whole adult population (figure 4).

The percentage reductions in asthma exacerbations in patients with blood eosinophils $<300$ or $\geqslant 300$ cells $\mu \mathrm{L}^{-1}$ and $\operatorname{IgE}<75$ or $\geqslant 75 \mathrm{IU} \cdot \mu \mathrm{L}^{-1}$ are shown in figure 5 , and indicate that omalizumab was effective in all these patient subgroups.

In minors $(\mathrm{n}=149), 110$ had blood eosinophils $\geqslant 300$ cells $\mu \mathrm{L}^{-1}$ and 39 had blood eosinophils $<300$ cells $\mu \mathrm{L}^{-1}$. Responders to omalizumab were also analysed using a cut-off of $600 \mathrm{cells} \cdot \mu \mathrm{L}^{-1}$. This cut-off was the median blood eosinophil count at T-12 in this subgroup and allowed a better distribution of the population: 80 patients had blood eosinophils $\geqslant 600$ cells. $\mu \mathrm{L}^{-1}$ and 69 patients had blood eosinophils $<600$ cells $\mu \mathrm{L}^{-1}$. Combined response to omalizumab treatment was $70.9 \%$ (95\% CI $\left.61.5-79.2 \%\right)$ in minors with blood eosinophils $\geqslant 300$ cells. $\mu \mathrm{L}^{-1}(\mathrm{n}=110)$ and $59 \%$ (95\% CI $\left.42.1-74.4 \%\right)$ in those with blood eosinophils $<300$ cells $\mu \mathrm{L}^{-1}(\mathrm{n}=39)$. With a cut-off of 600 cells $\mu \mathrm{L}^{-1}$, combined response reached $72.5 \%(95 \%$ CI $61.4-81.9 \%)$ for $\geqslant 600$ cells. $\mu \mathrm{L}^{-1} \quad(\mathrm{n}=80)$ and $62.3 \%$ (95\% CI $\left.49.8-73.7 \%\right)$ for $<600$ cells $\mu \mathrm{L}^{-1}(\mathrm{n}=69)$.
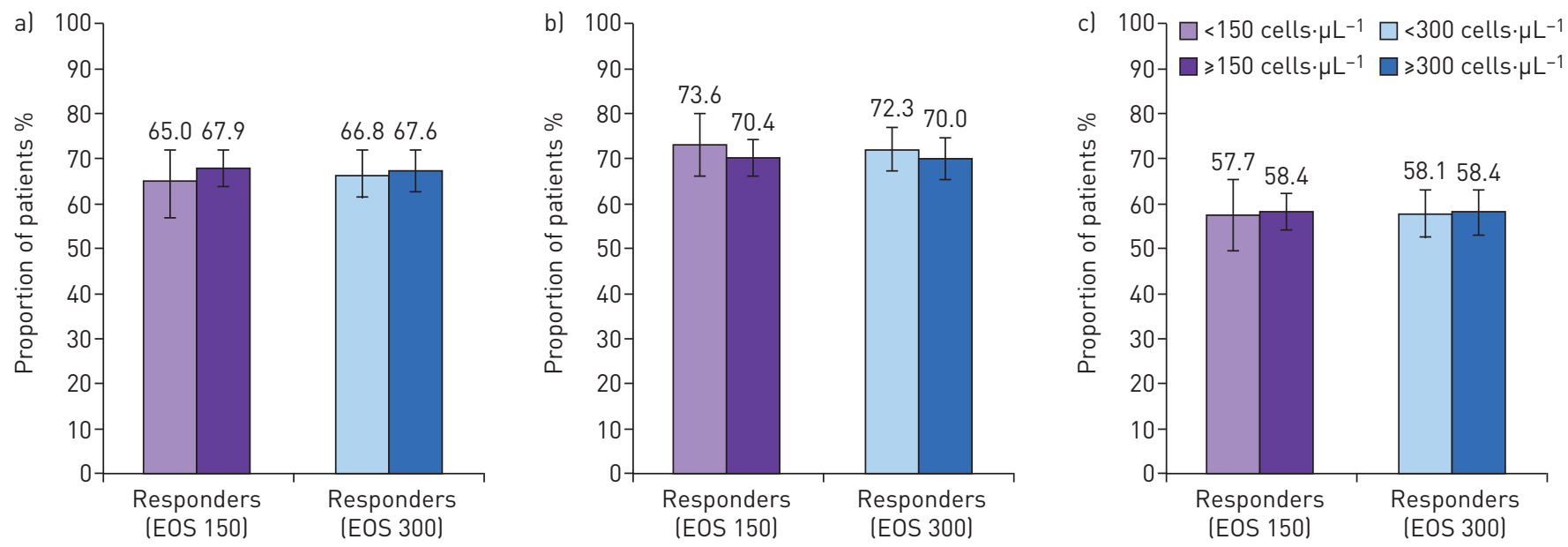

FIGURE 3 Responders to omalizumab treatment in adults ( $\geqslant 18$ years) at T4-6 (time of first effectiveness assessment after $4-6$ months of treatment) according to blood eosinophil count cut-off at 150 cells. $\mu \mathrm{L}^{-1}$ (“EOS 150": <150 cells. $\mu \mathrm{L}^{-1}, \mathrm{n}=163 ; \geqslant 150$ cells $\mu \mathrm{L}^{-1}, \mathrm{n}=560$ ) and 300 cells. $\mu \mathrm{L}^{-1}$ ("EOS 300": $<300$ cells. $\mu \mathrm{L}^{-1}, \mathrm{n}=346 ; \geqslant 300$ cells. $\mu \mathrm{L}^{-1}, \mathrm{n}=377$ ). GETE: Global Evaluation of Treatment Effectiveness. a) Responders based on physician's global evaluation (GETE). b) Responders based on a $\geqslant 40 \%$ decrease in the annual exacerbation rate. c) Combined responders (combination of GETE and exacerbation rate decrease). Error bars indicate $95 \%$ confidence intervals. 


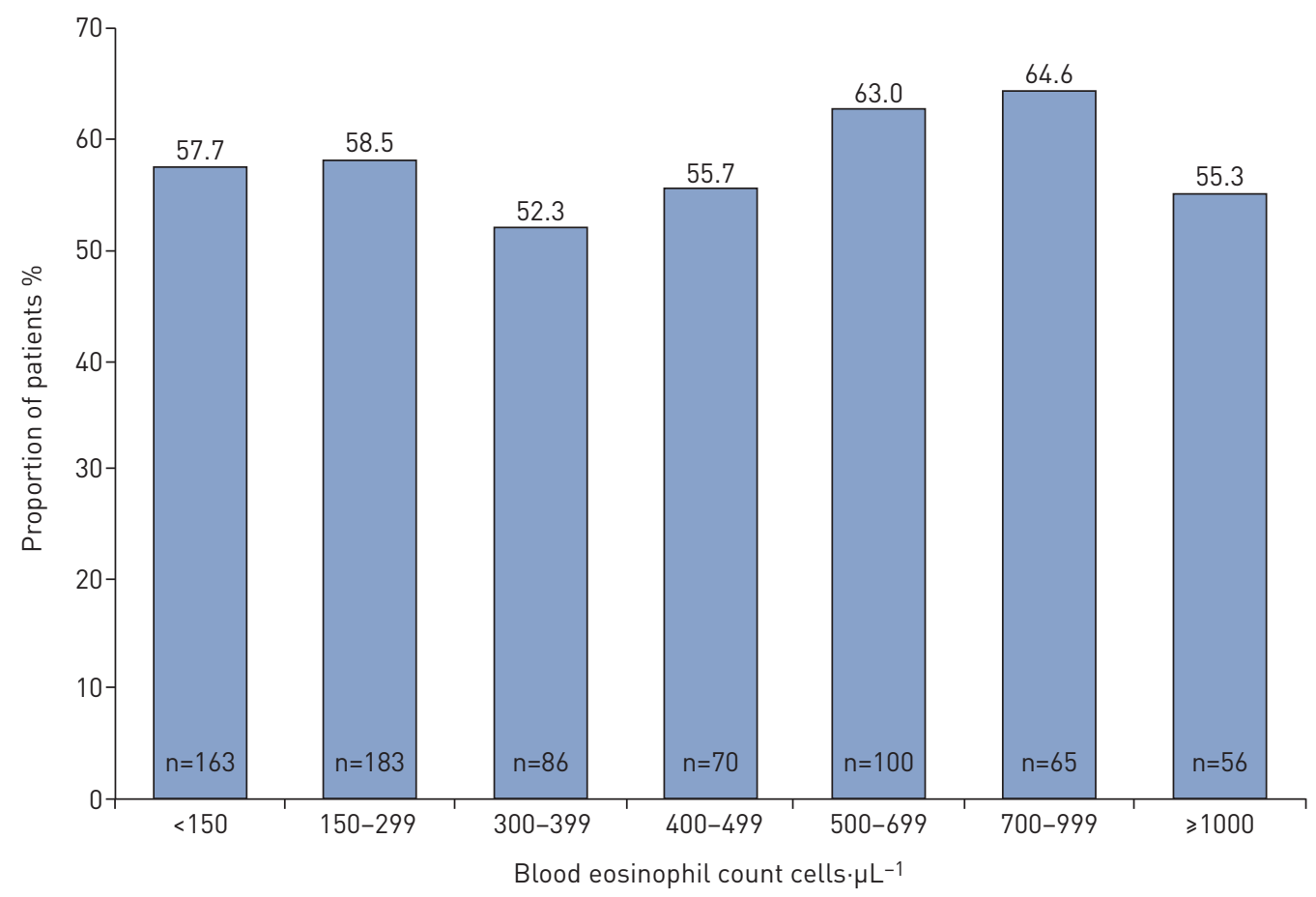

FIGURE 4 Combined responders to omalizumab treatment in adults ( $\geqslant 18$ years) according to the distribution of blood eosinophil count in the whole population.

All in all, the response rate was similar for adults and minors, irrespective of studied eosinophil cut-offs and for all definitions of response (table 4).

At T12, data for treatment effectiveness (including number of exacerbations, hospitalisations and modification in OCS therapy) were available for 706 of the study participants, with 577 adults and 129 minors completing 373 and 403 days of omalizumab therapy, respectively. The results were adjusted on a mean duration of 12 months. 50\% of minors (46 out of 92) and 61.9\% (179 out of 289) of adults

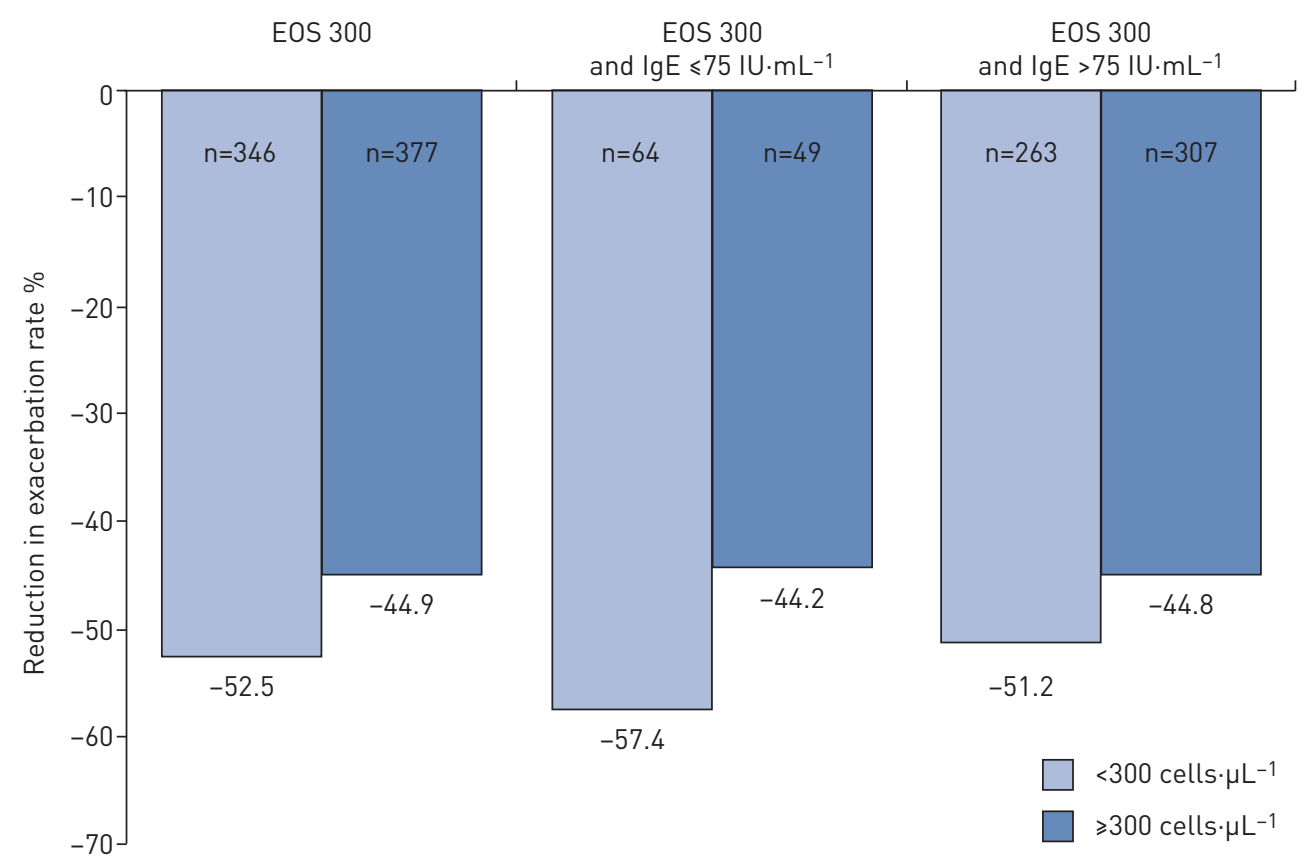

FIGURE 5 Reduction in asthma exacerbation rate according to blood eosinophil count (cut-off 300 cells. $\mu \mathrm{L}^{-1}$ ("EOS 300")) and serum IgE (cut-off $75 \mathrm{IU} \cdot \mu \mathrm{L}^{-1}$ ) in adults ( $\geqslant 18$ years) with severe allergic asthma. 
TABLE 4 Primary end-points at T4-6 (time of first effectiveness assessment after 4-6 months of treatment) by blood eosinophil count measured in the year prior to omalizumab initiation ( $T-12$ ) in minors (6-17 years) and adults ( $\geqslant 18$ years)

\begin{tabular}{|c|c|c|c|c|c|c|}
\hline & \multicolumn{2}{|c|}{$<300$ cells $\cdot \mu L^{-1}$} & \multicolumn{2}{|c|}{$\geqslant 300$ cells $\cdot \mu \mathrm{L}^{-1}$} & \multicolumn{2}{|c|}{ Total } \\
\hline & Minors & Adults & Minors & Adults & Minors & Adults \\
\hline Subjects & 39 & 346 & 110 & 377 & 149 & 723 \\
\hline Responder & $\begin{array}{c}25(64.1) \\
(47.2-78.8)\end{array}$ & $\begin{array}{c}231(66.8) \\
(61.5-71.7)\end{array}$ & $\begin{array}{c}90(81.8) \\
(73.3-88.5)\end{array}$ & $\begin{array}{c}255(67.6) \\
(62.7-72.3)\end{array}$ & $\begin{array}{c}115(77.2) \\
(69.6-83.7)\end{array}$ & $\begin{array}{c}486(67.2) \\
(63.7-70.6)\end{array}$ \\
\hline \multicolumn{7}{|l|}{ Reduction in annual exacerbation rate } \\
\hline \multicolumn{7}{|l|}{ Combination $^{+}$} \\
\hline Combined responder & $\begin{array}{c}23(59.0) \\
(42.1-74.4)\end{array}$ & $\begin{array}{c}201(58.1) \\
(52.7-63.4)\end{array}$ & $\begin{array}{c}78(70.9) \\
(61.5-79.2)\end{array}$ & $\begin{array}{c}220(58.4) \\
(53.2-63.4)\end{array}$ & $\begin{array}{c}101(67.8) \\
(59.7-75.2)\end{array}$ & $\begin{array}{c}421(58.2) \\
(54.5-61.8)\end{array}$ \\
\hline
\end{tabular}

Data are presented as n, n (\%) $\left(95 \%\right.$ Cl) or mean \pm SD. GETE: Global Evaluation of Treatment Effectiveness. ${ }^{\#}$ : physician's overall evaluation (GETE scale for symptoms control) (responders include excellent responders (complete control of asthma) and good responders (marked improvement); data not presented for nonresponders (discernible, no appreciable change or worseningl); ": decrease in the yearly rate of exacerbations with omalizumab la responder has a reduction of $\geqslant 40 \%$ in the yearly occurrence of exacerbations before and after omalizumab initiation); ${ }^{+}$: combination of both definitions (GETE and exacerbation rate decrease).

experienced at least one exacerbation during the 12 months of treatment (mean \pm sD $1.1 \pm 1.6$ and $1.4 \pm 2$, respectively). Compared with the 12 -month pre-treatment period, the exacerbation rates were reduced by $70.4 \pm 50 \%$ in minors and $58.6 \pm 67.8 \%$ in adults. $15.5 \%$ of minors (20 out of 129$)$ and $10.9 \%$ of adults (63 out of 577) were hospitalised at least once during the 12 months of treatment (mean \pm SD $0.2 \pm 0.6$ and 0.2 \pm 0.6 , respectively). The annual rate of hospitalisations was on average the same in minors and adults (mean \pm SD 0.2 \pm 0.6 ). Compared with the 12 month pre-treatment period, the mean reduction in hospitalisation rates was $73.2 \%$ in minors and $72.6 \%$ in adults.

A total of 243 adults were treated with OCS (mean daily dose $20.4 \mathrm{mg} \cdot \mathrm{day}^{-1}$ ) at T0. 195 patients $(80.2 \%)$ with OCS as maintenance treatment at To had a follow-up visit available at T12. At T12, 96 of these patients (49.2\%) had completely discontinued OCS therapy. Among those who were still being treated with an OCS, the majority $(62.1 \%)$ had decreased their median (IQR) daily dose by 10 (5-15) $\mathrm{mg} \cdot$ day $^{-1}$, which represented a median (IQR) reduction in daily OCS dose of 50\% (40-70\%). Omalizumab effectiveness (GETE, number of exacerbations and modification in OCS therapy) in adults with OCS as maintenance treatment was observed in patients with blood eosinophils $<300$ and $\geqslant 300$ cells $\mu \mathrm{L}^{-1}$ (data not shown).

Information on blood eosinophil count at T12 was available for 212 patients (173 adults and 39 minors). According to the GETE scale, excellent responder adult patients $(n=35)$ showed a $45.5 \%$ median decrease in blood eosinophil count, while good $(n=88)$ and nonresponders $(n=48)$ had a median decrease only of $20.1 \%$ and $0 \%$, respectively. Similar results were observed in minors, with a $55.7 \%$ and $53.3 \%$ decrease in excellent $(n=11)$ and good $(n=17)$ responders, while nonresponders $(n=10)$ presented a decrease of $11.4 \%$. These results suggest a decrease of the blood eosinophil count when SAA patients respond to omalizumab. The change was not statistically correlated to response status (ANOVA).

68 children (50 males (74\%)) were in the 6-12-year-old age group (mean \pm SD age $8.6 \pm 1.7$ years at omalizumab initiation). The median blood eosinophil count was 776 cells $\mu \mathrm{L}^{-1}$ and was $\geqslant 300$ cells $\mu \mathrm{L}^{-1}$ in $74 \%$ of cases. Omalizumab effectiveness evaluated at $\mathrm{T}_{4-6} 6$ by the treating pulmonologist or paediatrician using the GETE scale was excellent or good in $80.9 \%$ of cases (95\% CI $69.5-89.4 \%)$. It was $73.7 \%$ (95\% CI 48.8-90.9\%) for blood eosinophils $<300$ cells $\mu \mathrm{L}^{-1}$ and $83.7 \%$ (95\% CI 70.3-92.7\%) for blood eosinophils $\geqslant 300$ cells $\mu \mathrm{L}^{-1}$. The mean \pm SD yearly rate of asthma exacerbations decreased from $5.7 \pm 3.3$ prior to omalizumab therapy to $1.4 \pm 3.3$ at $\mathrm{T} 4-6$. Combined response to omalizumab treatment was reached in $75 \%$ (95\% CI 63.0-84.7\%) of cases, $68.4 \%(43.5-87.4 \%)$ for blood eosinophils $<300$ cells $\mu \mathrm{L}^{-1}$ and $77.6 \%(63.4-$ $88.2 \%$ ) for blood eosinophils $\geqslant 300$ cells $\mu \mathrm{L}^{-1}$.

64 patients were current smokers and 180 were ex-smokers (mean \pm SD $18.0 \pm 13.4$ pack-years). There was a trend for reduced effectiveness in current and ex-smokers versus nonsmokers. Combined response to omalizumab treatment was reached in $48.4 \%$ (95\% CI 36.2-60.7\%) of current smokers, 55.6\% (95\% CI 48.3-62.81\%) of ex-smokers and 61.2\% (95\% CI 56.7-65.8\%) of nonsmokers. When the blood eosinophil 
count was $<300$ cells $\mu \mathrm{L}^{-1}$, combined response was reached in $42.5 \%$ (95\% CI $27.2-57.8 \%$ ) of current smokers, 56.8\% (95\% CI 46.5-67.2\%) of ex-smokers and 62.0\% (95\% CI 55.3-68.7\%) of nonsmokers.

\section{Discussion}

This report suggests that omalizumab response in patients with SAA does not vary with blood eosinophil count: omalizumab appears to be as effective in patients with "high" eosinophils $\left(\geqslant 300\right.$ cells $\left.\mu \mathrm{L}^{-1}\right)$ as in those with "low" eosinophils $\left(<300\right.$ cells $\left.\mu \mathrm{L}^{-1}\right)$. These results remain similar with all other studied blood eosinophil cut-offs and for all definitions of response.

These real-life findings confirm those already published in the omalizumab arm of the EXTRA study post hoc analysis that showed similar exacerbation rates during the 48-week omalizumab treatment period in low ( $<260$ cells $\mu \mathrm{L}^{-1}$ at baseline) and high $\left(\geqslant 260\right.$ cells $\mu \mathrm{L}^{-1}$ at baseline) eosinophil subgroups of 0.65 and 0.70 , respectively [18]. However, the reduction in exacerbation rate seen with omalizumab (versus placebo) was lower in patients with low versus high eosinophil count at baseline [18]; a possible explanation for this difference could be the high exacerbation rate in the high eosinophil group treated with placebo [18]. Similarly, in a post hoc analysis of the INNOVATE study, omalizumab produced a greater reduction in exacerbation rate in patients with higher versus lower baseline eosinophil count [19] and a recent post hoc analysis of two clinical studies has also shown a greater reduction in exacerbation rate with omalizumab in patients with higher versus lower eosinophil count [20]. In the latter study, only $3 \%$ of patients had been hospitalised for an exacerbation in the previous year, suggesting that patients had moderate to severe asthma, while a $45 \%$ reduction in exacerbation rate with omalizumab in patients with a low eosinophil count at baseline showed clinical effectiveness even with low eosinophils [20]. Possible explanations for the differences seen between these post hoc analyses and our study include STELLAIR being a real-life study rather than a randomised, controlled clinical trial, STELLAIR was not a post hoc analysis and the patient population here had more severe asthma. Irrespective of this, what is clear from the STELLAIR study and the other post hoc analyses published to date is that omalizumab is effective at reducing the exacerbation rate of patients with SAA and while some studies have demonstrated a greater response in patients with higher baseline eosinophil count, this does not rule out the effectiveness of omalizumab treatment.

The STELLAIR study provides new data regarding the distribution of eosinophil count in SAA patients before starting Global Initiative for Asthma Step 5 therapies (add-on with either tiotropium, anti-IgE or anti-IL-5 therapies). The study shows different mean blood eosinophil counts for adults ( 451 cells. $\mu \mathrm{L}^{-1}$ ) and minors ( 685 cells. $\mu \mathrm{L}^{-1}$ ) in the 12 months prior to omalizumab initiation. $73.8 \%$ of minors and $52.1 \%$ of adults had blood eosinophils $\geqslant 300$ cells $\mu \mathrm{L}^{-1}$. Such adults could be eligible for anti-IL- 5 therapies. This figure could be underestimated as a number of patients were treated by OCSs. In a post hoc analysis of the INNOVATE clinical trial [19], 59\% (245 patients) of the 12-75-year-old patients had blood eosinophils $\geqslant 300$ cells $\mu \mathrm{L}^{-1}$ at baseline. Similar results were found in a post hoc analysis of the EXTRA trial with $52 \%$ of patients having a median baseline blood eosinophil count $\geqslant 260$ cells $\mu \mathrm{L}^{-1}$ [18]. The proportions of patients with SAA and blood eosinophils $\geqslant 300$ cells $\mu \mathrm{L}^{-1}$ are close for these three studies that assessed patients with severe asthma eligible for biotherapy. A cut-off of 400 cells $\mu \mathrm{L}^{-1}$ has also been used in several publications focusing on eosinophil count in asthmatic patients whatever the severity [21, 22]; these studies showed a prevalence rate of $18-26 \%$ of patients with blood eosinophils $\geqslant 400 \mathrm{cells} \cdot \mu \mathrm{L}^{-1}$. A recent large UK cohort of 130000 asthmatic patients found blood eosinophils $>400$ cells $\mu \mathrm{L}^{-1}$ in $16 \%$ of patients (and in 26\% of severe patients) (Step 4 and 5 according to the British Thoracic Society therapy steps) [23]. In our study, $40 \%$ of adults had blood eosinophils $\geqslant 400$ cells $\mu \mathrm{L}^{-1}$ at baseline. Taken together, these findings show that there is considerable overlap between SAA and SEA patients, both corresponding to type 2 (Th2-high) asthma.

The main limitation of the study resides in its retrospective design. However, the patient characteristics and omalizumab effectiveness are similar to the results of previous studies conducted during clinical development [6-8] and in real-life settings [9-15], both for adults and minors. The STELLAIR study confirms the differences between severe asthma in adults and in minors: adults are more frequently female (60.9\%), whereas minors are more often male (63.1\%). Selection bias was also reduced by asking all participating investigators to include consecutive patients corresponding to strict selection criteria. Bias was addressed in part by the electronic case report form that was developed to minimise missing data using appropriate controls, particularly for end-points with mandatory fields. Data check and review confirmed that patients were effectively eligible for omalizumab and very few patients $(n=7)$ were excluded from the analysis. Furthermore, to ensure the robustness of the results, response to omalizumab was defined by three sets of criteria that completely converged. Finally, the STELLAIR study is the largest real-world omalizumab study conducted in France, including $>10 \%$ of all omalizumab-treated SAA patients in the country. Taken together, it is likely that these results can be generalised to SAA patients eligible for omalizumab and managed by pulmonologists and paediatricians in France and other comparable settings. 
Although various biological therapies with different mechanisms of action targeting each of the phenotypes exist or are under development, deciding who is best treated with which therapy is a challenging task [24]. Given the considerable overlap in SAA and SEA, physicians have to decide which therapeutic strategy will be more effective for a patient presenting SAA and SEA. The STELLAIR study results suggest that, conversely to antibodies targeting specifically the eosinophil activation pathway, omalizumab therapy is effective in eligible patients with SAA irrespective of the pre-treatment blood eosinophil count. These findings deserve to be further investigated by prospective studies assessing the clinical effectiveness of biologics targeting overlapping populations of patients with severe persistent allergic asthma and a high blood eosinophil count.

Acknowledgements: We thank the staff members at all the study centres for participating in this study, Matrix Consultants (France) for editorial services, and Ian Wright (UK) and Céline Thonnelier (France) for copyediting the final version of the submitted manuscript.

STELLAIR investigators: M. Agossou (Fort de France), C. Appere de Vecchi (Argenteuil), E. Barbare (Meaux), M. Barbry (Taden), C. Belleguic-Lebreton (Rennes), D. Benhamou (Bois-Guillaume Bihorel), A. Bentaleb (Amiens), A. Blanc (Aix en Provence), P. Bonniaud (Dijon), M. Bourgoin (Paris), J. Brouard (Caen), P-M. Broussier (Bois-Guillaume Bihorel), D. Caimmi (Montpellier), E. Catherinot (Suresnes), R. Chiron (Montpellier), M. Claussner-Paulignan (Forbach), P. Combe-Cayla (Villefranche de Rouergue), P. Cros (Brest), G. Dauriat (Paris), B. Delaisi (BoulogneBillancourt), G. Devouassoux (Lyon), T. Didi (Metz-Tessy), A. Didier (Toulouse), S. Dominique (Rouen), P. Dumont (Chauny), S. Dury (Reims), D. Dusser (Paris), M. Fayon (Bordeaux), M. Gainet-Brun (Besançon), G. Garcia (Le Kremlin-Bicêtre), L. Guilleminault (St Pierre de la Réunion), N. Hesse (Rennes), S. Jeandeau (Ste Feyre), V. Jubin (Bron), J. Just (Paris), N. Just (Roubaix), P-E. Kelkel (Chambery), A-S. Kerjan (Guingamp), A. Labbe (ClermontFerrand), H. Laize (Sceaux), Y. Laoudi (Aulnay-sous-Bois), M. Larrousse (Toulon), Y. Le Guen (St Grégoire), O. Leleu (Abbeville), G. Letanche (Venissieux), G. Lorillon (Paris), G. Mangiapan (Créteil), E. Marangoni (St Die des Vosges), S. Marchand-Adam (Tours), P. Martin (Metz-Vantoux), C. Maurer (Montfermeil), F. Menivale (Colombiers), B. Mouget (Vandoeuvre les Nancy), D. Muller (Metz), M. Nasr (Vienne), L. Nguyen (Bordeaux), J-P. Oster (Colmar), H. Pegliasco (Marseille), B. Philippe (Pontoise), I. Pin (La Tronche), C. Pison (La Tronche), A. Proust (Nîmes), A. Prudhomme (Tarbes), C. Radu (Strasbourg), A. Rakoto (Chalon sur Saône), C. Rochefort-Morel (Rennes), C. Rolland-Debord (Paris), P. Romand (Contamine sur Arve), P. Roux (Besançon), C. Sattler (Le Kremlin Bicêtre), D. Siret (St Nazaire), C. Taillé (Paris), L. Tetu (Toulouse), A-I. Tiotiu (Vandoeuvre les Nancy), C. Tummino (Marseille), J. Valcke (Vanves), S. Verdier (Perpignan), P. Vigneron (Lorient), J. Virally (Aulnay-sous-Bois), S. Wanin (Paris), all in France.

Author contributions: M. Humbert, M. Molimard, L. Mala and V. Le Gros contributed to data acquisition, and data analysis and interpretation. M. Humbert and M. Molimard contributed to the study concept, design, analysis and interpretation. C. Taillé and J. Just contributed to analysis and interpretation. All authors were involved in the preparation and review of the manuscript and approved the final version to be submitted.

Support statement: Novartis Pharmaceuticals. The funder of the study contributed to the study design, data interpretation and writing of the report. The corresponding author had full access to all of the data and the final responsibility to submit for publication. Funding information for this article has been deposited with the Crossref Funder Registry.

Conflict of interest: M. Humbert has relationships with drug companies including AstraZeneca, GSK, Novartis, Roche, Sanofi/Regeneron and Teva. In addition to being an investigator in trials involving these companies, relationships include consultancy services and membership of scientific advisory boards. C. Taillé received personal fees from Kappa Santé, during the conduct of the study; and received personal fees from and acted as a study investigator for AstraZeneca, Boehringer, Novartis and ALK, received personal fees from Chiesi and Teva, received grants and personal fees from and acted as a study investigator for GSK, and acted as a study investigator for Sanofi, outside the submitted work. L. Mala is an employee of Novartis Pharma SAS. V. Le Gros is an employee of Novartis Pharma SAS. J. Just received personal fees from ALK and Stallergenes, and grants and personal fees from Novartis, outside the submitted work. M. Molimard received personal fees from Novartis Pharma, GSK and Boehringer Ingelheim (for consulting agreement and participation on scientific advisory boards), and was employed by the University of Bordeaux, during the conduct of the study; and received an unconditional educational grant from Novartis Pharma, outside the submitted work.

\section{References}

1 Chung KF, Wenzel SE, Brozek JL, et al. International ERS/ATS guidelines on definition, evaluation and treatment of severe asthma. Eur Respir J 2014; 43: 343-373.

2 Reddel H, Bateman E, Becker A, et al. A summary of the new GINA strategy: a roadmap to asthma control. Eur Respir J 2015; 46: 622-639.

3 Froidure A, Mouthuy J, Durham SR, et al. Asthma phenotypes and IgE responses. Eur Respir J 2016; 47: 304-319.

4 European Medicines Agency. Summary of product characteristics Xolair. 2009. www.ema.europa.eu/docs/en_GB/ document_library/EPAR___Product_Information/human/000606/WC500057298.pdf Date last accessed: March 16, 2018. Date last updated: October 10, 2016.

5 Humbert M, Busse W, Hanania NA, et al. Omalizumab in asthma: an update on recent developments. J Allergy Clin Immunol Pract 2014; 2: 525-536.

6 Humbert M, Beasley R, Ayres J, et al. Benefits of omalizumab as add-on therapy in patients with severe persistent asthma who are inadequately controlled despite best available therapy (GINA 2002 step 4 treatment): INNOVATE. Allergy 2005; 60: 309-316.

7 Hanania NA, Alpan O, Hamilos DL, et al. Omalizumab in severe allergic asthma inadequately controlled with standard therapy: a randomized trial. Ann Intern Med 2011; 154: 573-582. 
8 Kulus M, Hébert J, Garcia E, et al. Omalizumab in children with inadequately controlled severe allergic (IgE-mediated) asthma. Curr Med Res Opin 2010; 26: 1285-1293.

9 Molimard M, de Blay F, Didier A, et al. Effectiveness of omalizumab (Xolair) in the first patients treated in real-life practice in France. Respir Med 2008; 102: 71-76.

10 Brusselle G, Michils A, Louis R, et al. 'Real-life' effectiveness of omalizumab in patients with severe persistent allergic asthma. The PERSIST study. Respir Med 2009; 103: 1633-1642.

11 Grimaldi-Bensouda L, Zureik M, Aubier M, et al. Does omalizumab make a difference to the real-life treatment of asthma exacerbations? Results from a large cohort of patients with severe uncontrolled asthma. Chest 2013; 143: 398-405.

12 Braunstahl G-J, Chen C-W, Maykut R, et al. The eXpeRience registry: the 'real-world' effectiveness of omalizumab in allergic asthma. Respir Med 2013; 107: 1141-1151.

13 Braunstahl G-J, Chlumský J, Peachey G, et al. Reduction in oral corticosteroid use in patients receiving omalizumab for allergic asthma in the real-world setting. Allergy Asthma Clin Immunol 2013; 9: 47.

14 Deschildre A, Marguet C, Salleron J, et al. Add-on omalizumab in children with severe allergic asthma: a 1-year real life survey. Eur Respir J 2013; 42: 1224-1233.

15 Deschildre A, Marguet C, Langlois C, et al. Real-life long-term omalizumab therapy in children with severe allergic asthma. Eur Respir J 2015; 46: 856-859.

16 Buhl R, Humbert M, Bjermer L, et al. Severe eosinophilic asthma: a roadmap to consensus. Eur Respir J 2017; 49: 1700634.

17 Tran TN, Zeiger RS, Peters SP, et al. Overlap of atopic, eosinophilic, and $\mathrm{T}_{\mathrm{H}}$ 2-high asthma phenotypes in a general population with current asthma. Ann Allergy Asthma Immunol 2016; 116: 37-42.

18 Hanania NA, Wenzel S, Rosén $\mathrm{K}$, et al. Exploring the effects of omalizumab in allergic asthma: an analysis of biomarkers in the EXTRA study. Am J Respir Crit Care Med 2013; 187: 804-811.

19 Manga V, Humbert M, Djukanovic R, et al. Blood eosinophils and serum IgE predict response to omalizumab in patients with severe allergic asthma: INNOVATE trial post-hoc analysis. J Allergy Clin Immunol 2016; 137: AB16.

20 Casale TB, Chipps BE, Rosén K, et al. Response to omalizumab using patient enrichment criteria from trials of novel biologics in asthma. Allergy 2018; 73: 490-497.

21 Schleich FN, Chevremont A, Paulus V, et al. Importance of concomitant local and systemic eosinophilia in uncontrolled asthma. Eur Respir J 2014; 44: 97-108.

22 Tran TN, Khatry DB, Ke X, et al. High blood eosinophil count is associated with more frequent asthma attacks in asthma patients. Ann Allergy Asthma Immunol 2014; 113: 19-24.

23 Price DB, Rigazio A, Campbell JD, et al. Blood eosinophil count and prospective annual asthma disease burden: a UK cohort study. Lancet Respir Med 2015; 3: 849-858.

24 Bousquet J, Brusselle G, Buhl R, et al. Care pathways for the selection of a biologic in severe asthma. Eur Respir J 2017; 50: 1701782 